\title{
A fuzzy mixed integer programming for marketing planning
}

\author{
Abolfazl Danaei ${ }^{\mathrm{a}}$, Mohammad Hemmati ${ }^{\mathrm{b}}$ and Ghazaleh Naseri Kohneshahri ${ }^{\text {* }}$
}

${ }^{a}$ Department of Management, Semnan Branch, Islamic Azad university, Semnan, Iran

${ }^{b}$ Department of Management, Science and Research Branch, Islamic Azad university, Semnan, Iran

CHRON I C L E ABS T RACT

Article history:

Received October 28, 2013

Received in revised format

25 November 2013

Accepted 18 January 2014

Available online

January 192014

Keywords:

Marketing planning

GIS system

Mixed integer programming

IPHONE

\begin{abstract}
One of the primary concerns to market a product is to find appropriate channel to target customers. The recent advances on information technology have created new products with tremendous opportunities. This paper presents a mixed integer programming technique based on McCarthy's 4PS to locate suitable billboards for marketing newly introduced IPHONE product. The paper considers two types of information including age and income and tries to find the best places such that potential consumers aged 25-35 with high income visit the billboards and the cost of advertisement is minimized. The model is formulated in terms of mixed integer programming and it has been applied for potential customers who live in city of Tabriz, Iran. Using a typical software package, the model detects appropriate places in various parts of the city.
\end{abstract}

\section{Introduction}

During the past few years, there have been substantial change on communication industry and many people could talk to each other using different techniques such as internet, mobile phone, etc. On the other hand, there has been growing competition among mobile service providers. People may prefer to change their mobile services based on the new services provided by a new rival. Mobile service providers compete with others using different advertisement methods including television advertisement, billboard exposure, etc. Apple has been one of the most successful firms for offering mobile phone in the world and it competes with its competitors through different types of products and services. One of the well-known methods for product development is to do market development through McCarthy's 4PS (McCarthy, 1960; Westervelt, 1999). Anderson and Taylor (1995), for instance, evaluated Jerome McCarthy's 4Ps paradigm from an historical and philosophical

*Corresponding author. Tel: +989370404697

E-mail addresses: danaei11@yahoo.com (G. Naseri Kohneshahri) 
perspective. They reviewed criticisms of the 4Ps paradigm and explained that it had proven to be sufficiently robust for contemporary marketing applications.

McCarthy's 4PS idea reduced the marketing mix to 4 elements: product, price, place and promotion. The product perspective of marketing is associated with the characteristics of the actual products or services, and how it is associated with the end-user's requirements and wishes. The scope of a product normally includes supporting elements such as branding, packaging, warranties, guarantees, and support. Pricing is associated with the process of setting a price for a product, including discounts. The price does need not have to be necessarily monetary; it can simply be what is exchanged for the product or services, e.g. time, energy, or attention. Place or distribution is associated with how the product receives to the customer; for instance, point-of-sale placement or retailing. Finally, promotion includes advertising, sales promotion, publicity, Direct Marketing, Digital Marketing, etc.

Geographic information systems (GIS) (Peng \& Tsou, 2003) play essential role for the management of urban disaster risk, periodic updating of building, more specifically in developing countries where urbanization rates relatively high. However, collecting data on the characteristics of buildings and lifelines through full ground surveys is normally time-consuming and frustrating (Pundt, 2002). Montoya (2003) performed an investigation on the use of an off-the-shelf low-cost and rapid technique of data collection for the development of a building inventory and GIS. They developed a method, which consists of a sequence of stages, where the first stage involves the implementation of RS and GIS for stratification and mission planning purposes. The second stage also includes usage of GPS and DV for the creation of spatially referenced images and the third stage incorporates the implementation of GIS for display and analysis.

\section{The propose method}

The proposed model of this paper uses McCarthy's 4PS idea to develop a method for marketing planning in one of Apple's IPHONE device. Fig. 1 demonstrates the structure of the proposed method. In this paper, we present a mixed integer programming to determine the appropriate places for billboard advertisement. The proposed model minimizes the sum of advertisement by considering two primary constraints, which are associated with age and income. Let $x_{i j}$ be a binary variable, which is one if advertisement type $j$ is located in region $i$, and zero, otherwise. In addition, $c_{i j}$ is the cost of having advertisement type $j$ in region $i$. We assume there are $n$ different regions and $m$ types of billboard advertisements. Therefore, the objective function is defined as follows,

$$
\min z=\sum_{i=1}^{m} \sum_{j=1}^{n} c_{i} x_{i j}
$$

The first constraint is as follows,

$$
\sum_{j=1}^{n} X_{i j} \leq 1, \quad i=1, \cdots, n \quad j=1, \cdots, m
$$

which means there is at most one advertisement in each region. The proposed model of this paper considers the constraints of age and income in fuzzy form (Zadeh, 1965). Let $a_{i}^{1}$ and $a_{i}^{2}$ be the percentage of people aged 25-35 and good income in region $i$, respectively. In addition, let $\alpha$ be the percentage of uncertainty. Therefore, we have,

$$
\sum_{i=1}^{m} \sum_{j=1}^{n}\left(-\operatorname{Ln}\left(1-a_{i}^{1}\right)\right) X_{i j} \geq-\operatorname{Ln}(1-\alpha)
$$


$\sum_{i=1}^{m} \sum_{j=1}^{n}\left(-\operatorname{Ln}\left(1-a_{i}^{2}\right)\right) X_{i j} \geq-\operatorname{Ln}(1-\alpha)$.

There are $m \times n$ variables associated with the proposed study of this paper. In addition, there are $m \times$ $n+2$ constraints with the proposed study of this paper. As we can observe from Eq. (3) and Eq. (4) are stated in fuzzy form. For the proposed study of this paper, $a_{i}^{1}, a_{i}^{2}$, and $\alpha$, which are associated with age and income are obtained based on GIS technique as well as consulting with decision makers.

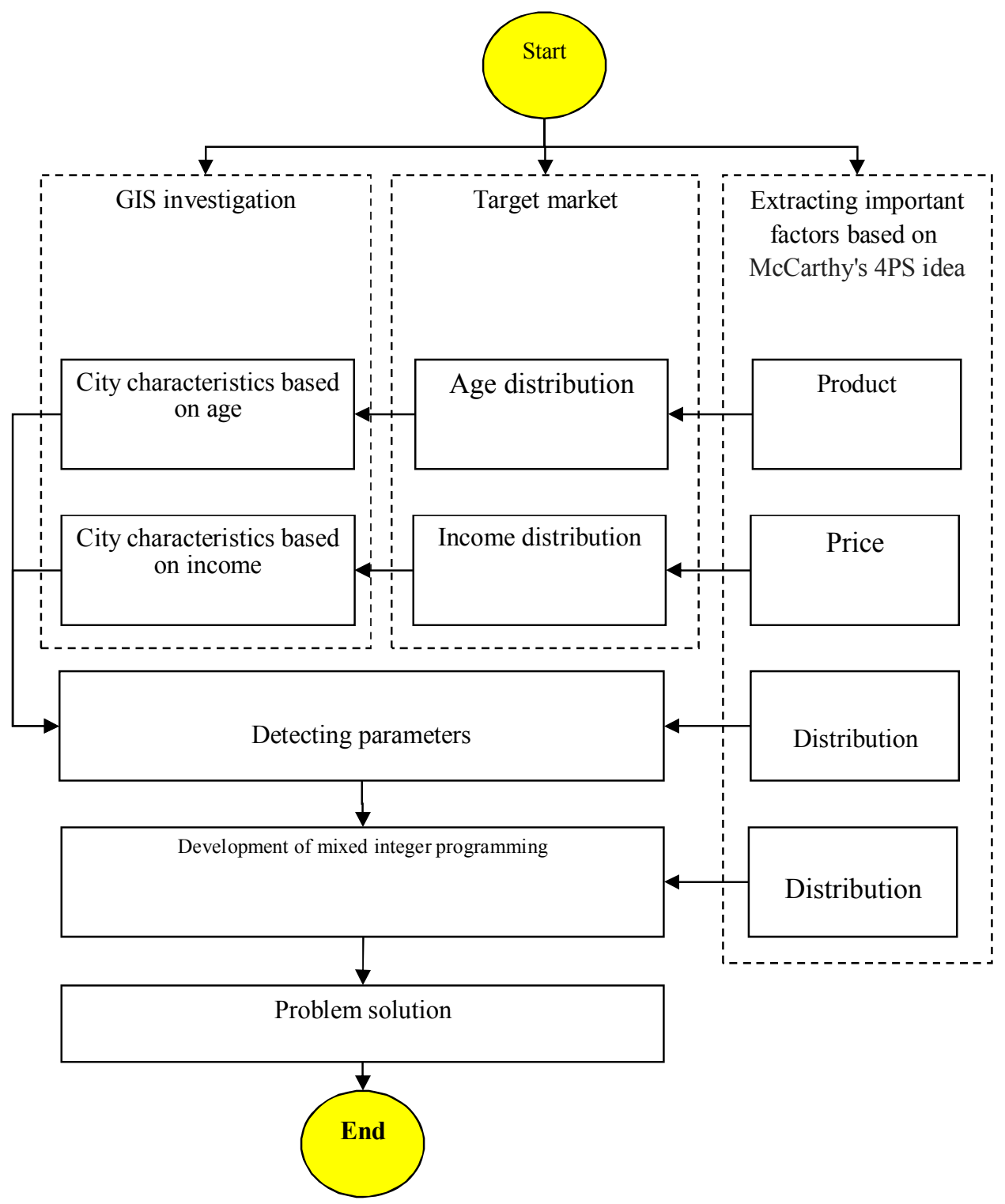

Fig. 1. The proposed method

\section{Results and conclusion}

In this section, we present details of our findings on implementation of the proposed model. The study has been accomplished in city of Tabriz, located in west part of Iran. The city consists of 21 different regions. In each region, we may have different types of advertisement depending on the size and the cost. The proposed study of this paper has been solved using mixed integer programming software package and four regions have been suggested as optimal solution strategy. In our survey, 
GIS has been proven to an effective method for reducing the cost of advertisement. There is no doubt that firms spend more than before on advertising their products and services. IPHONE is one of the most popular devises for communication in the world and it the producer of this product, Apple, has been able to build the most expensive business unit in the world. The proposed study has used GIS system to determine the necessary information of the people who may be interested in many products and services. It can help us determine people's personal characteristics such as age, gender, etc.

\section{Acknowledgement}

The authors would like to thank the anonymous referees for constructive comments on earlier version of this paper.

\section{References}

Anderson, L. M., \& Taylor, R. L. (1995). McCarthy's 4PS: Timeworn or time-tested?. Journal of Marketing Theory and Practice, 3(3), 1-9.

McCarthy, Jerome E. (1960). Basic Marketing. A Managerial Approach. Homewood, IL: Richard D. Irwin.

Montoya, L. (2003). Geo-data acquisition through mobile GIS and digital video: an urban disaster management perspective. Environmental Modelling \& Software, 18(10), 869-876.

Peng, Z. R., \& Tsou, M. H. (2003). Internet GIS: distributed geographic information services for the internet and wireless networks. Wiley.com.

Pundt, H. (2002). Field data collection with mobile GIS: Dependencies between semantics and data quality. GeoInformatica, 6(4), 363-380.

Westervelt, J. D. (1999). Modeling mobile individuals in dynamic landscapes. International Journal of Geographical Information Science, 13(3), 191-208.

Zadeh, L. A. (1965). Fuzzy sets. Information and control, 8(3), 338-353. 